\title{
Ileal Atresia
}

National Cancer Institute

\section{Source}

National Cancer Institute. Ileal Atresia. NCI Thesaurus. Code C101026.

A congenital malformation characterized by the absence of a normal opening in a part of the ileum. 